\title{
Breast conservation with batwing mastopexy for the management of giant juvenile fibroadenoma: A case report of a 12-year-old girl
}

\author{
Dev juvenil fibroadenomun yönetiminde batwing mastopeksi yöntemi ile meme \\ koruyucu cerrahi: 12 yaşında bir kız çocuk olgu sunumu
}

Bülent Çitgez ${ }^{1}$, Elif Baran ${ }^{1}$, Banu Yiğit ${ }^{1}$, Soysal Baş ${ }^{2}$, Aydın Eray Tufan ${ }^{1}$, Hamdi Özşahin ${ }^{1}$

\begin{abstract}
Fibroadenomas are benign breast tumours consisting of epithelial and stromal components. Most of them are about 1 to $2 \mathrm{~cm}$ in size. It is defined as "giant" when the fibroadenoma is larger than $5 \mathrm{~cm}$, weighs more than 500 $\mathrm{g}$ or occupies for at least $80 \%$ of breast volume. It is usually encountered in patients of less than 20 years of age. Progressively growing mass and its large size cause a suspicion of malignancy. It presents as unilateral macromastia that causes breast asymmetry. Excellent cosmetic results cannot be obtained with simple excision in this situation. We aimed to present a case of a 12-year-old patient with a diagnosis of giant juvenile fibroadenoma. In this case, we performed surgical excision with Batwing mastopexy of the breast to achieve optimal symmetry with contralateral breast.
\end{abstract}

Key words: Batwing, fibroadenoma, mastopexy, breast, symmetry
${ }^{1}$ University of Health Sciences, Sisli Hamidiye Etfal Medical Practice and Research Center, Department of General Surgery, Istanbul, Turkey.

2 University of Health Sciences, Sisli Hamidiye Etfal Medical Practice and Research Center, Department of Plastic and Reconstructive Surgery, Istanbul, Turkey.

\section{ID}

BC: 0000-0001-9759-8798

EB: 0000-0001-8477-6719

BY: 0000-0001-7606-9352

SB: 0000-0002-4657-1613

AET: 0000-0001-9129-883

HÖ: 0000-0001-8517-172X

Informed Consent: The written consent was received from the patient who was presented in this study.

Hasta Onamı: Çalışmada sunulan hastadan yazılı onam alınmıștır.

Conflict of Interest: No conflict of interest was declared by the authors.

Çıkar Çatışması: Yazarlar çıkar çatışması bildirmemişlerdir.

Financial Disclosure: The authors declared that this case has received no financial support. Finansal Destek: Yazarlar bu olgu için finansal destek almadıklarını beyan etmişlerdir.

Geliş Tarihi / Received: 24.09.2020

Kabul Tarihi / Accepted: 05.12.2020

Yayın Tarihi / Published: 15.12.2020

Sorumlu yazar / Corresponding author:

Banu Yiğit

Adres/Address: Hasan Cevdet Paşa Street, Mim Apartment No.8,D-5, Nisantasi/İstanbul, Turkey. e-mail: banuyigit149@gmail.com

Tel/Phone: +905352094056

Copyright $\odot$ ACEM

Anahtar kelimeler: Batwing, fibroadenom, mastopeksi, meme, simetri 


\section{Introduction}

Fibroadenomas are benign breast tumours consisting of epithelial and stromal elements and occur in approximately 10 percent of women [1]. The exact etiology and pathogenesis underlying fibroadenomas is not clearly understood. It has been reported that it can be associated with the use of hormonal contraceptives or detection of Epstein-Barr virus [2]. Most of them are about 1 to $2 \mathrm{~cm}$ in size. Growing rapid of fibroadenomas usually slows down when they reach 2 to $3 \mathrm{~cm}$ in size [3]. It is defined as "giant" when the fibroadenoma is larger than $5 \mathrm{~cm}$, weighs more than $500 \mathrm{~g}$ or occupies for at least $80 \%$ of breast volume. Giant fibroadenoma of the breast usually occurs in patients younger than 20 years of age $[4,5]$. Fibroadenomas are ought to be benign lesions but they have tendency to grow faster. This feature may suggest the possibility of malignancy and it may need a comprehensive differential diagnosis. The epithelial component of fibroadenoma may be the origin of the malignant tumors especially lobular carcinoma. Unilateral fibroadenomas occur with a serious breast asymmetry due to their rapid enlargement; therefore they cannot be improved with just a simple surgical excision. Batwing mastopexy is an oncoplastic technique for periareolar lesions in the upper central breast and especially for lesions in pitotic breasts [6]. This method also can be applied in the treatment of giant fibroadenomas.

\section{Case report}

A 12-year-old female patient referred to the surgical department of our hospital with a complaint of fast-growing, painful mass of her right breast that she first noticed 6 months ago. Patient reported that her menarche onset age was 11 and stated that her menstrual cycle pattern was also normal. The patient has no family history of breast disease or family history for cancer.

Physical examination, showed a palpable mass larger than $10 \mathrm{~cm}$ in upper outer quadrant of the right breast. The mass was almost completely filling the right breast. The mass caused the unilateral enlargement of the right breast and asymmetrical appearance compared to her left side (Figure1). Clinical examination of the left breast was normal and there was no axillary lymphadenopathy.

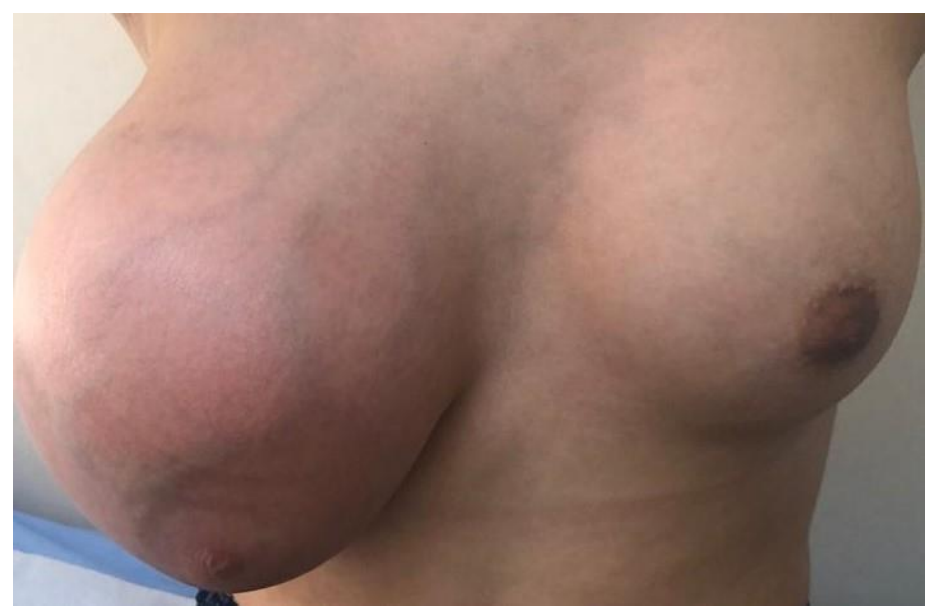

Figure 1: Enlarged right breast due to a giant juvenile fibroadenoma mass.

Breast ultrasonography was performed via high frequency (6-11 MHz) linear transducer. Breast ultrasound revealed a homogeneous, hypoechoic, solid mass in upper outer quadrant of the right breast with a diameter of $134 \times 91 \mathrm{~mm}$ that filled the breast almost completely. No axillary nodes were noticed in the bilateral axilla. Phyllodes tumors, juvenile breast hypertrophy, giant lipomas and hamartomas were considered for differential diagnosis. Ultrasound guided core needle biopsy (CNB) was performed and the biopsy result was reported to be compatible with pseudoangiomatous stromal hyperplasia. Due to clinical suspicion and cosmetic reasons, the patient was subjected to surgical intervention. Surgical excision was performed using the Batwing mastopexy technique. The postoperative follow-up was uneventful; the patient had excellent cosmetic results. Breasts were a in perfect symmetry and the right breast matched to the size and shape of the other breast (Figure 2). The macroscopic assessment of pathology specimens showed homogeneous cut surface and encapsulated lobular contour with a tumour size of $22 \times 18 \times 7 \mathrm{~cm}$ (Figure 3,4). The excised mass weighed $1600 \mathrm{~g}$. After surgical excision, histopathology confirmed the diagnosis of giant juvenile fibroadenoma with pseudoangiomatous stromal hyperplasia in the focal areas. Atypia or pleomorphism was not observed.

Written informed consent was obtained from parent for publication.

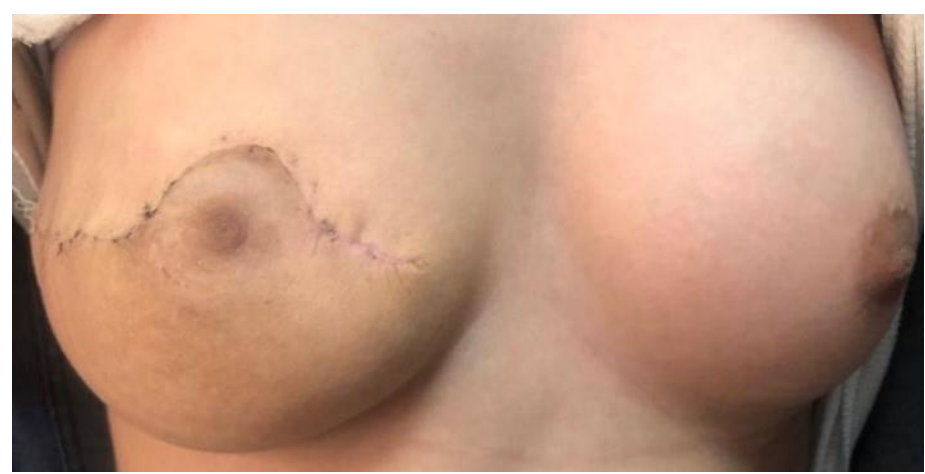

Figure 2: 1 month after fibroadenoma excision and breast reconstruction with Batwing mastopexy.

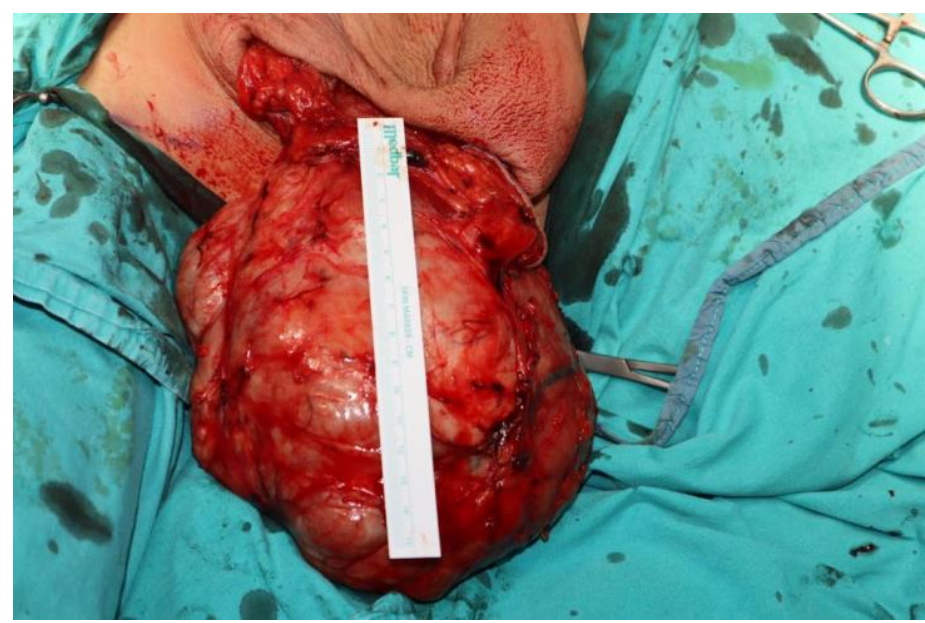

Figure 3: Macroscopic view of the excised giant fibroadenoma with well circumscribed lobulated contours.

\section{Discussion}

We report a case with juvenile giant fibroadenoma underwent a wide excision of the tumor in a 12-year old girl. Fibroadenomas are called "juvenile fibroadenoma" when the patient is under 18 years of age and usually encountered during the adolescent period [7]. The prevalence of fibroadenoma during the adolescent period is $2.2 \%$ and $1-8 \%$ of fibroadenomas are giant juvenile fibroadenomas $[8,9]$. "Giant" fibroadenomas are called fibroadenomas larger than $5 \mathrm{~cm}$ or heavier than 500 grams or when the mass is greater than $80 \%$ of the normal 


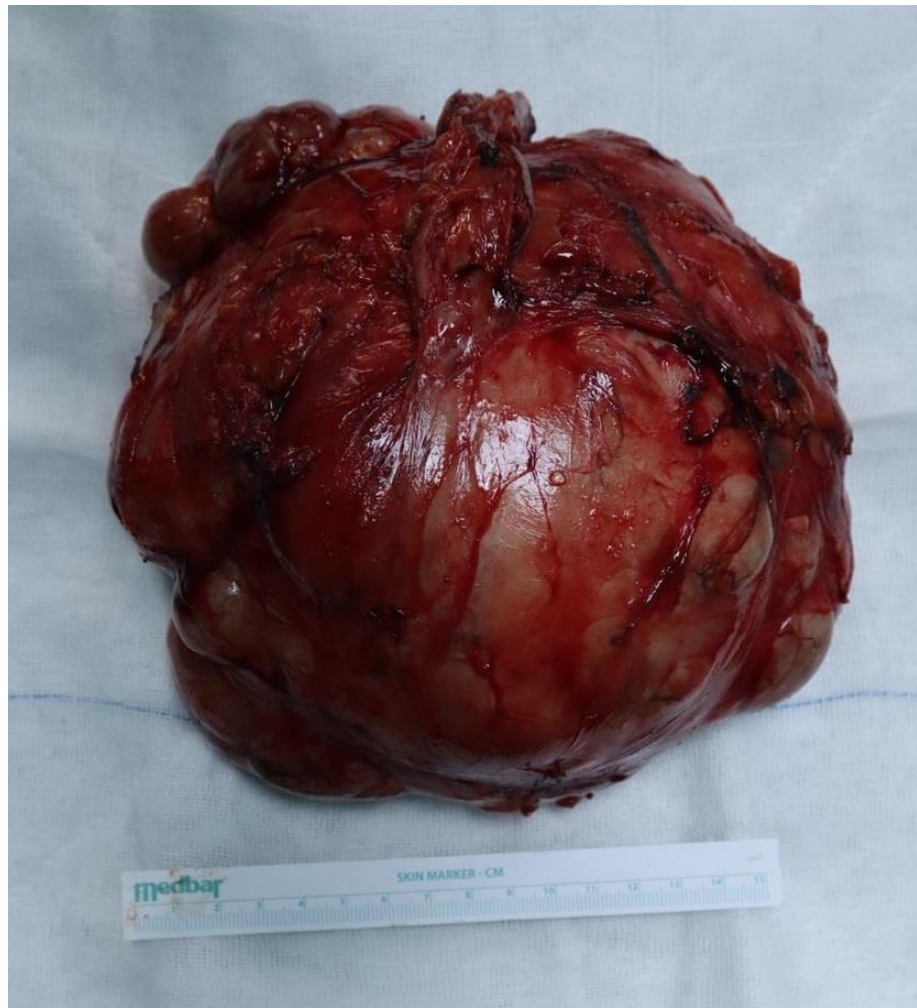

Figure 4: Macroscopic view of the excised giant fibroadenoma with well circumscribed lobulated contours.

breast size [4]. In our case, fibroadenoma was complex, larger than $5 \mathrm{~cm}(22 \mathrm{~cm})$ and its weight was heavier than $500 \mathrm{~g}(1600$ g). Histologically fibroadenomas divided into two groups which are simple and complex. Most of them are benign breast lesions, but the risk of malignancy increases in complex fibroadenomas. Complex fibroadenomas are differentiated from simple ones by containing different cell types [10]. Etiological factors have not been exactly known, but reproductive hormones or history of previous breast traumas are thought to be the reasons [11, 12].

Juvenile fibroadenomas are usually presented as palpable masses of the breast that are hard and movable lumps with well-defined margins. They are painless masses when they are small in size. They may become tender or painful as they increase in size or before menstrual period. In our case, she presented with a painful and rapidly enlarging unilateral breast mass. Fibroadenomas can cause breast asymmetry, nipple retraction, atrophy of surrounding breast parenchymal tissue and widened superficial blood vessels. Giant juvenile fibroadenomas may mimic malignant breast tumours because of their rapid growth. Whereas malignant transformation is rare in fibroadenomas; phyllodes tumors and adenocarcinomas should be evaluated in differential diagnosis $[13,14]$.

Ultrasonography is an important diagnostic method for the diagnosis of fibroadenoma and detecting masses in fibroglandular breasts. If it is required, imaging studies such as mammography or magnetic resonance imaging studies should also be performed. In our case, ultrasound was performed as the first imaging method in accordance with the age and the breast tissue density of the patient. Fine needle aspiration biopsy (FNAB) and CNB can be used in diagnosis of the suspected fibroadenoma [15, 16]. Diagnostic value of FNAB varies according to the physicians who performed and evaluated the biopsy. CNB is a more invasive procedure and has complications such as hematoma, pain or discomfort. CNB is more accurate and reliable than FNAB but the definitive diagnostic method is excisional biopsy.
There are various management methods of juvenile fibroadenoma ranging from observation to surgical management. Conservative approach is usually favored in small fibroadenomas because they are not precursor for breast cancer, and about $10 \%$ to $40 \%$ of fibroadenomas resolve spontaneously [8]. There are various surgical or non-surgical treatment methods such as simple excision, cryoablation, vacuum-assisted excisional biopsy available to remove fibroadenomas [17]. Choosing the right technique is very important, especially in terms of aesthetic. Cryoablation has negative effects on pathological evaluation and may cause suspicious residual calcifications on mammograms. It also has size limitations to perform cryoablation. It can be applied to lesions larger than $4.2 \mathrm{~cm}$ in diameter [18]. Fibroadenomas which are less than $3 \mathrm{~cm}$ are removed by ultrasound-guided vacuum-assisted excisional biopsy [19]. Breast conservation is usually feasible for fibroadenomas. Mastectomy is an aggressive method and, if it is necessary, then nipple conserving methods are recommended. Reconstructive techniques generally come into prominence in multiple fibroadenomas, giant fibroadenomas or recurrent fibroadenomas. Mastopexy, reduction mammoplasty or augmentation are supplementary techniques which should also be evaluated individually. In our case, we performed Batwing mastopexy that is also called an inverted $\mathrm{V}$ or omega plasty because of the incision shape. We use a semi-circular line at the upper margin of the nipple areola complex (NAC) and another semi-circular parallel line above with two angled incisions to connect these two lines in a wing-like fashion to remove the lesion in this technique. The defect is closed by pulling up the inferior breast tissue. It may be used for lesions in the upper or central breast but it should be irrelevant with NAC [20]. During surgical excision, it is necessary to pay attention to the integrity of the fibroadenoma capsule. Disrupting the capsule of the fibroadenoma in surgical treatment increases the risk of recurrence and makes it difficult to define the borders in the case of malignancy or phyllodes tumor. The recurrence rate is about $33 \%$ at the 5-year follow-up after excision [21]. The surgical excision was performed with a safety margin of approximately 1 $\mathrm{cm}$. During the 1-year follow-up, she was monitored with ultrasound scanning; no recurrence or deformity of the breast was reported and the patient is satisfied with the aesthetic result.

In conclusion, symmetry is an important feature in bilateral organs such as breasts. In the giant fibroadenoma with a significant breast asymmetry, excision with the Batwing mastopexy technique has succeeded in achieving symmetry with the opposite breast in these patients. The Batwing mastopexy technique provides easy access for tumor excision and also adjusts the position and the size of the NAC to maintain normal breast and symmetry.

\section{References}

1. Kaufman CS, Littrup PJ, Freeman-Gibb LA, Smith JS, Francescatti D, Simmons R et al: Officebased cryoablation of breast fibroadenomas with long-term follow-up. Breast J 2005; 11: 344-350.

2. Kleer CG, Tseng MD, Gutsch DE, Rochford RA, Wu Z, Joynt LK et al. Detection of Epstein-Barr virus in rapidly growing fibroadenomas of the breast in immunosuppressed hosts. Mod Pathol 2002;15:759-764.

3. Oprić S, Oprić D, Gugić D, Granić M. Phyllodes tumors and fibroadenoma common beginning and different ending. Coll Antropol. 2012 Mar;36(1):235-41.

4. Citgez B, Yigit B, Ucak R, Yetkin SG. Giant fibroadenoma of the breast: A case report of a 37-year-old woman during the second trimester of pregnancy. J Surg Med. 2020;4(7):613-615. 
5. Makkar N, Singh S, Paul S, Sandhu MS, Kumar A. Bilateral Giant Juvenile Fibroadenoma of Breast. J Clin Diagn Res. 2017 Jun;11(6):ED10-ED12.

6. Matkowski R, Szynglarewicz B, Kasprzak P, Forgacz J, Skalik R, Zietek $\mathrm{M}$ et al. Batwing mastopexy as oncoplastic surgical approach to periareolar tumors in upper quadrants. Tumori 2012;98:421-7.

7. Huang IC, Li PC, Ding DC. Recurrent juvenile fibroadenoma of the breast in an adolescent: A case report. Medicine (Baltimore) 2018 May;97(20):e10765.

8. Lee M, Soltanian HT. Breast fibroadenomas in adolescents: current perspectives. Adolesc Health Med Ther. 2015; 6: 159-163.

9. Giannos A, Stavrou S, Gkali C, Chra E, Marinopoulos S, Chalazonitis A et al. A prepubertal giant juvenile fibroadenoma in a 12-year-old girl: Case report and brief literature review. Int J Surg Case Rep. 2017;41:427-430.

10. Nassar A, Visscher DW, Degnim AC, Frank RD, Vierkant RA, Frost M et al. Complex fibroadenoma and breast cancer risk: a Mayo Clinic Benign Breast Disease Cohort Study. Breast Cancer Research \& Treatment 2015;153(2):397-405.

11. Izadpanah A, Karunanayake M, Izadpanah A, Sinno H, Gilardino M. An atypical growth of a giant fibroadenoma after trauma. J Pediatr Adolesc Gynecol 2012;25:e115-7.

12. Li J, Humphreys K, Ho PJ, Eriksson M, Darai-Ramqvist E, Lindström LS et al. Family history, reproductive, and lifestyle risk factors for fibroadenoma and breast cancer. JNCI Cancer Spectr. 2018; 2:pky051.

13. Ismail S, Alaidi S, Jouni S, Kassab Y, Al-Shehabi Z. Recurrent giant fibroadenomas with transformation to cystosarcoma phyllodes in a 17year-old girl: a rare case report from Syria. J Med Case Rep. 2019 Dec 21;13(1):378.

14. Park CA, David LR, Argenta LC. Breast asymmetry: presentation of a giant fibroadenoma. Breast J 2006;12:451-61.

15. Smith GEC, Burrows P. Ultrasound diagnosis of fibroadenoma - is biopsy always necessary? Clin Radiol. 2008 May;63(5):511-5.

16. Łukasiewicz E, Ziemiecka A, Jakubowski W, Vojinovic J, Bogucevska M, Dobruch-Sobczak K. Fine-needle versus core-needle biopsy - which one to choose in preoperative assessment of focal lesions in the breasts? Literature review. J Ultrason 17:267-274, 2017.

17. Pruthi S, Jones K. Nonsurgical management of fibroadenoma and virginal breast hypertrophy. Semin Plast Surg. 2013; 27: 62-66.

18. Littrup PJ, Freeman-Gibb L, Andea A, White M, Amerikia KC, Bouwman D. Cryotherapy for breast fibroadenomas. Radiology. 2005 Jan;234(1):63-72.

19. Bugdaycı O, Kaya H, Arıbal E. Ultrasound Guided Therapeutic Excisional Vacuum Assisted Biopsy in Breast Fibroadenomas. J Breast Health. 2017 Apr; 13(2): 74-76.

20. Kumar HH, Rahman NKF, Ramesh RS, Raghunandan GC. Adding bit of esthetics with science modification of batwing mastopexy for breast conservation in a young patient with giant fibroadenoma breast. J Cancer Res Ther. 2019 Jul-Sep;15(5):1173-1176.

21. Song BS, Kim EK, Seol H, Seo JH, Lee JA, Kim DH et al. Giant juvenile fibroadenoma of the breast: a case report and brief literature review. Ann Pediatr Endocrinol Metab. 2014;19(1):45-48. . 